\title{
Object Knowledge and the Emergence of Language ${ }^{1}$
}

\author{
Karin Lifter \\ Northeastern University \\ Lois Bloom \\ Teachers College, Columbia University
}

Citation: Lifter, K., \& Bloom, L. (1989). Object play and the emergence of language. Infant Behavior and Development, 12, 395-423.

\begin{abstract}
Infants' spontaneous play with objects was examined for evidence of developments in object knowledge in relation to the emergence of words and the single- word period in language development. Subjects were 7 girls and 7 boys, from different ethnic and economic backgrounds, who were studied longitudinally from 9 months to 26 months of age. Two types of displacements of objects in relation to one another were identified in the children's play: Separations and Constructions. The development of Constructions was associated with the emergence of words, and Constructions increased with age while Separations decreased. The development of Specific constructions, which account for knowledge of the particular properties of objects, was more strongly associated with a Vocabulary Spurt at the end of the single-word period than with chronological age. Despite the wide variation in the infants' ages when developments in language and play were reached, relations between achievements in the two domains were consistent among them, as confirmed with the Friedman test, $\mathrm{p} \leq .001$. The results are discussed in terms of the cognitive developments required for play with objects and saying words.
\end{abstract}

The emergence of language in the single-word period coincides with developments in sensorimotor thought. Early studies in children's language suggested a serial connection between developments in the two domains, with language dependent upon developments in thought (e.g., Bates, 1976; Bloom, 1970; Bowerman, 1973; Brown, 1973; Edwards, 1973; Ingram, 1978; Macnamara, 1972; Nelson, 1973a; Schlesinger, 1971; Sinclair, 1970; Slobin, 1973). The theoretical assumption was that object knowledge is required for talking about objects and actions. In particular, both knowledge of objects in general (i.e., object permanence, as conceptualized by Piaget, 1954) and knowledge about specific objects (i.e., object concepts) were expected to be required for developments in language (Bloom, 1973; Brown, 1973; Sinclair, 1970).

Subsequent studies to test the relation between the development of language and the development of object permanence identified object permanence with children's performance on ordinal scales of sensorimotor development (e.g., Uzgiris \& Hunt, 1975). One general result in the studies that used sensorimotor scales was that the beginning and end of the single-word period in language coincide with the beginning and end of the final period in sensorimotor development that is ordinarily described in global terms as Sensorimotor Stage 6 (e.g.,

${ }^{1}$ This research was supported by funds provided by the National Science Foundation and by the Spencer Foundation to Lois Bloom, and by a National Institute of Mental Health predoctoral fellowship MH o7748 to Karin Lifter. Preliminary results were presented to the biennial meeting of the Society for Research in Child Development, Toronto, April, 1985, as part of the symposium "From Infancy to Language: Contributions from Affect, Cognition and Intentionality," and to the New York Child Language Group, New York, December, 1985. We are grateful to Richard Beckwith, Joanne Capatides, Jeremie Hafitz, and Matthew Rispoli for their involvement in all phases of the research project of which this study is a part. We thank Margaret Honey, Tresmaine Rubain, and Joy Vaughn for their assistance in collecting the data; Virginia Brennan, Suzanne Gottlieb, Mariette Newton-Danilo, and Pia Wikstrom for their considerable help in coding and reducing the data for analysis; Lorraine Harner, Margaret Lahey, Annick Mansfield, and Hollis Scarborough for their helpful comments; and Kathleen Bloom and Jane Monroe for their advice on statistical questions. KL is grateful to Laurel Furumoto and Dean Edward Stettner for the opportunity to be Visiting Scholar at Wellesley College during the intermediate phases of manuscript preparation.

Correspondence and requests for reprints should be sent to Karin Lifter, Department of Applied Psychology, 404 International Village, 360 Huntington Avenue, Northeastern University, Boston, MA 02115. 
Corrigan, 1978). Progress in passing particular tasks on the object permanence scales was not correlated with global measures of language (e.g., Bates, Begnigni, Bretherton, Camaioni, \& Volterra, 1979; Corrigan, 1978; Miller, Chapman, Branston, \& Reichle, 1980; L. Siegel, 1981; Smolak, 1982; Zachry, 1972, 1978). However, other studies have demonstrated correspondences between object permanence performance on the scales and more particular aspects of language (e.g., Gopnik, 1984; Gopnik \& Meltzoff, 1987; McCune-Nicolich, 1981; Menn \& Hazelkorn, 1977; Smolak \& Levine, 1984; Tomasello \& Farrar, 1984). We might conclude, then, that the results from all these studies, taken together, have been inconclusive.

Three problems have been raised with respect to using performance on sensorimotor scales to compare developments in cognition and language (Bloom, Lifter, \& Broughton, 1985). First, scale performance is diagnostic of level of achievement and does not provide information about the kinds of object knowledge that develop in this period. Second, object behaviors in performing the tasks on the sensorimotor scales are elicited and subject to the task constraints in a standardized test situation. Such elicited behaviors are not as comparable to spontaneous language as is spontaneous play with objects. Third, correlational analyses are not definitive for determining whether a developmental relationship exists between two domains (Belsky \& Most, 1981; Smolak \& Levine, 1984). Most correlational analyses assume a serial or parallel model. A serial model implies causality, with later behaviors in a sequence dependent on earlier behaviors. In a parallel model, behaviors develop together without a necessary relationship between them. However, the relation between developments in cognition and language are more likely to be overlapping than either serial or parallel (Bloom, Lifter, \& Broughton, 1985).

Given these problems with studies that have compared developments in language with performance on sensorimotor scales, one purpose of the present study was to infer developments in object knowledge from children's displacements of objects in their spontaneous play. The selection of object displacements as the variable for this study of object knowledge was guided by Piaget's narrative descriptions of his own infants' object displacements. These were the basis of his conceptualization of object permanence which, in turn, informed certain hypotheses in the early language studies concerning relations between language and sensorimotor thought. (A study of the development of object search, also described by Piaget as important for object permanence in this same period, is reported in Bloom, Lifter, \& Broughton, 1985; Lifter, 1982.)

The second purpose of this study was to compare (a) developments in object knowledge inferred from spontaneous play with (b) elicited task performance on sensorimotor scales and (c) progress in learning words in this period. The two general expectations in this study were as follows. First, developments in sensorimotor scale performance were expected to predict the beginning and end of the single-word period, as has been found in other studies (e.g., Bates et al., 1979; Corrigan, 1978). Second, play activities were expected to increase in both frequency and variety as the children increased in age (e.g., Rubin, Fein, \& Vandenburg, 1983). However, the more important expectation for the present study was that developments in object knowledge would be related to developments in language, with particular developments in play more closely associated with developments in language than with chronological age.

We propose that developments in play provide evidence of both general object knowledge, from which developments in object permanence can be inferred, and specific object knowledge, from which developments in object concepts can be inferred. General object knowledge includes knowing that objects exist in space and time as separate entities that can be acted upon and moved in relation to one another. This knowledge of objects in general is abstracted from unidirectional and then reversible actions with objects and is the basis of object permanence (Piaget, 1954; Piaget \& Inhelder, 1969). Moving objects in relation to the self and other objects provide the infant with opportunities to discover unidirectional and reversible action patterns (Gratch, 1975). Knowledge of object concepts, on the other hand, is more specific knowledge of objects that includes the perceptual and functional attributes that differentiate objects from one another. Therefore, the extent to which the children's actions with the objects took account of the specific properties of objects provided information we used for inferring the object-specific knowledge that underlies the formation of object concepts.

Analyses of variance were used to determine the empirical sequence of developments in object knowledge. Rankorder statistics were used to infer the relationship between developments in object knowledge and progress in learning words. 


\section{METHOD}

Subjects

Fourteen infants, 7 boys and 7 girls, from varied ethnic and economic backgrounds in the New York metropolitan area were the subjects of this study. The children were firstborn, from families where only English was spoken in the homes. Their mothers were not employed outside of the home when they began their participation in the study.

\section{Procedures}

Data were collected from monthly laboratory playroom observations of the children from about 8 to 26 months and parent diaries of the early words the infants said and understood at home. The scale for The Development of Visual Pursuit and the Permanence of Objects was administered, according to the procedures outlined by Uzgiris and Hunt (1975), during monthly home visits until 15 months and then in the playroom immediately following the observations for the rest of the data collection period. Both the 1-hour playroom sessions and the home visits were video recorded. Each infant and mother dyad interacted with only one pair of investigators, and the investigators and infant/mother dyads were matched for ethnicity. The infants and mothers were visited at home before the data collection began and then saw the investigators both at home and in the playroom each month. They gave every indication that they were relaxed and comfortable in the playroom sessions.

The playroom was furnished with a child-sized table with two chairs and a plastic slide. The video camera was mounted on a 3 - $\mathrm{ft}$ high movable tripod in the playroom, and one investigator maneuvered the camera so that the infant was in view all the time. A group of toys was placed in the middle of the room before the mother and infant arrived, and five additional groups of toys were brought into the playroom by a second investigator every $8 \mathrm{~min}$ thereafter, according to a schedule. The same toys were presented, in the same order, at each observation for all the children. The toys were chosen to counterbalance (a) possible boy/girl interest (e.g., truck, doll) and (b) potential for manipulative play (e.g., nesting boxes) and enactment play (e.g., baby doll, miniature silverware). (See the Appendix for a list of the playroom toys and a description of the configurations in which the toys were presented to the infants.) Each mother was asked to play with her child as she would if she had a free hour at home. A snack of cookies with juice for the children and coffee or tea for the mothers intervened in the schedule of toy presentation after the first half hour.

The video playback $(1 / 2$ inch Beta) was interfaced with a microcomputer (Apple II +) for computer-assisted data transcription and coding. The children's speech and their play were transcribed and coded independently, by different persons, in separate passes through the data. A computer-readable time code (SMPTE FOR.A), recorded on the second sound track of the videotapes at the time of the observations, allowed the separate transcription and coding passes through the tapes to be merged. The coded data were transferred to an IBM-XT for integrated analyses.

\section{Categories of Object Play}

We focused on those displacement activities in which the infants moved one object in relation to another object (e.g., taking a bead out of a container, placing one nesting box into another, feeding a doll with a spoon) with deliberate volition to perform the action. The criterion for "volition" was that the child first oriented to the object and then acted on it. The child was credited with any attempt at the displacement, whether ultimately successful or not, and chance encounters with the objects (e.g., accidentally dropping a bead into a box) were not included. Coding categories and decision rules were based upon the child's actions with the objects, independent of accompanying vocalization. Thus, the coding decisions avoided the confound inherent in the distinction between manipulative and symbolic play, where symbolic play depends upon what the child says. Such a confound is particularly problematic when the goal of the investigation is to compare developments in language and play (Huttenlocher \& Higgins, 1978; Rocissano, 1982).

All displacements, where the infant moved one object in relation to another, were identified. The coding categories for these displacements are presented schematically in Figure 1. The left branching categories (for example, Separations and Given constructions, Given and Generic constructions, and so forth) are mutually exclusive, with no overlap between them. The right branching categories are hierarchical and represent successive differentiation among the constructions. For example, Specific constructions were also Imposed, and 
Animate Surrogate constructions were a kind of Specific construction. These distinctions among the children's displacements and the resulting categories allowed us to perform quantitative analyses of relative frequency and criterion-based analyses of qualitative change for inferring development in object knowledge.

The first distinction was based on direction of movement. The children either moved objects apart, Separations (e.g., taking a peg person out of the seesaw), or moved objects together to create a configuration, Constructions (e.g., putting a peg person into the seesaw). The separating activities were not analyzed further, and the remaining distinctions were subcategorizations of constructed relations.

Constructions were categorized as either Given or Imposed. In the Given relations, the children brought two objects together into a relation that was the same as that in which the objects were introduced in the playroom originally (e.g., putting a peg person into the seesaw; putting one nesting box into another). For the Imposed constructions, in contrast, the children created a relation between the objects that was different from the relation between the objects originally presented to them (e.g., putting a family figure onto the seesaw; putting a peg person into a nesting box). Given relations were not analyzed further, and the remaining distinctions were subcategorizations of Imposed relations.

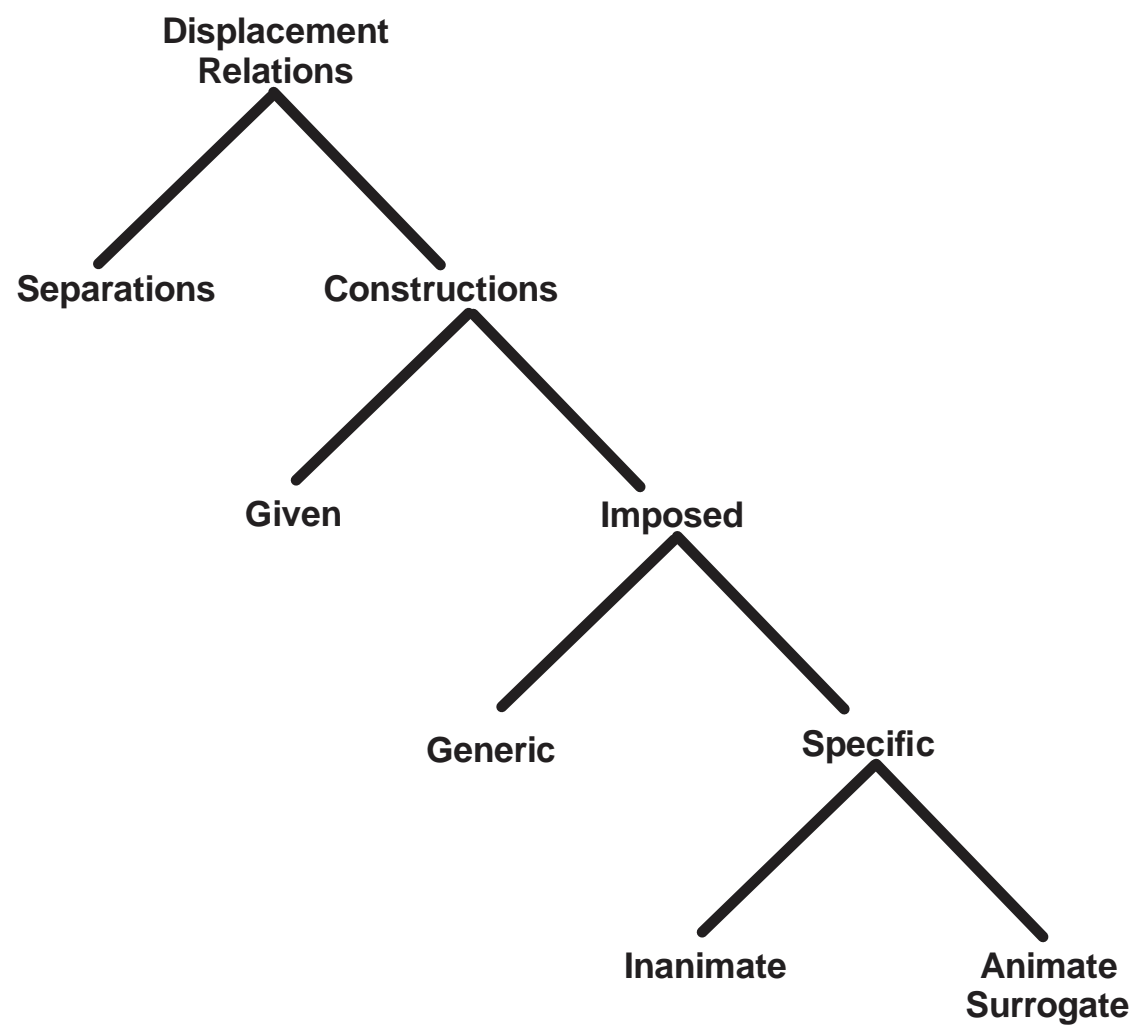

Figure 1. Successive subcategorization of constructing behaviors.

\section{Displacement Relations}

Imposed relations were either Generic or Specific. Generic constructions made use of those common properties of objects which afforded containment or support (e.g., putting silverware, family figures, or beads into a box; putting the peg people, beads, or small truck onto a flat surface). Specific constructions, in contrast, made use of more particular properties of individual objects in relation to one another (e.g., stringing beads; using a toy spoon to feed the doll). Generic relations were not subcategorized. Two subcategories of Specific constructions were identified. Animate Surrogate relations were constructed when the child used a replica of a person or animal in an enactment (e.g., feeding the doll with a spoon; giving a family figure a ride on a rubber horse). Other Specific relations were constructed with inanimate objects (e.g., putting beads on the string; rolling the small truck on the wooden roadway). 
In sum, the schematic presentation of the coding categories in Figure 1 captures two features of this analysis of play activities. One was a difference in form: moving objects apart (separating) or together (constructing). The second was differences in content: the difference between Generic and Specific relations, and the difference between Specific relations with an animate surrogate or inanimate object.

\section{Criteria for Developments in Object Knowledge}

In addition to the frequencies of displacements in these categories, two sets of criteria were used to assess object knowledge, one for emergence and one for achievement, in order to determine if the categories were ordered developmentally and compare qualitative developments in object knowledge with developments in language.

The criteria for emergence of a category were a minimum frequency of five actions, which included at least two different actions. For example, for the emergence of constructions, the infant was required to construct a configuration with two objects at least five times during the observation, and those five constructions had to include at least two different relations (for example, putting a peg person into the seesaw and also putting the peg person or some other object into a nesting box).

The criteria for achievement required both greater frequency and increased diversity of actions, making achievement a more stringent measure of developmental change than emergence. The first two criteria for achievement were twice the criteria for simple emergence: a minimum of 10 actions, with at least 4 different actions. A third criterion was used to evaluate the relative frequency of a category, given the expectations that (a) the actions in all the categories of play would increase in absolute frequency over time, and (b) earlier kinds of actions would continue even though new actions appeared. The relative frequency criterion was an assessment of qualitative developmental change, for example, as represented by an increase in constructions that were imposed relative to given relations and, among imposed relations, an increase in specific relations relative to generic relations, and so forth. This third criterion for achievement was at least a $40 \%$ increase in the relative frequencies of behaviors in the different categories or subcategories. This means that development of constructions was considered an achievement for a child when $40 \%$ or more of the child's object displacements, for example, were constructions (as opposed to separations). Although some children might have demonstrated achievement with an increase in relative frequency of $60 \%$ or $80 \%$ in a category, all of the children showed an increase of at least $40 \%$ in that category, given the minimum frequency and diversity criteria. For this reason, $40 \%$ was used as the criterion for developmental change.

In sum, three kinds of dependent variables were used to assess developments in object knowledge: the frequency of behaviors within a category or subcategory, emergence of new categories of behavior, and achievement of stability within a category. Emergence of the categories of object play provided evidence of new capacities from which qualitative change in underlying thought could be inferred. Achievement, in contrast, suggested a shift to mastery and stabilization of the knowledge that the activities required.

\section{Criteria for Developments in Language}

Three reference periods in the transition to language were identified for each child in order to determine the relation of developments in object knowledge to developments in language. Thus, the children's language-related behaviors were transcribed for all the monthly observations in order to identify those developments that could define the transition to language. Although the children were observed monthly in the playroom, the analyses of object play centered on those observations that marked transitional change in their language development. Such a strategy of focus on times of transition has been advocated for longitudinal studies by Emde and Harmon (1984) and Connell and Furman (1984). For this purpose, we identified two developments that we called First Words and Vocabulary Spurt in relation to a PreSpeech baseline. Each of these three reference points was, in turn, represented by a 3-month period to provide a wide enough window for identifying relations between developments in language and developments in object knowledge. The infants' object displacements were examined for evidence of object knowledge within each month in each of these three 3-month time periods.

The PreSpeech (PreSp) baseline was age-determined and included the playroom observations at 9, 10, and 11 months of age. The occurrence of First Words (FW) was a measure of emergence and consisted of a 3-month window. The FW target month was the first use of at least one spontaneous, conventional word said at least two times in the playroom. The FW window included this target month along with the preceding month (FW - 1) and 
the month that followed $(\mathrm{FW}+1)$. Thus, emergence in language was identified with the FW target (the criterion observation) along with the month before and the month after the target. Although the infants' ages for the PreSp baseline were the same for all of them, by definition, their ages differed widely at FW ( $M=13.8$ months; range $=$ 10-18 months). In addition, the mothers of 10 of the 14 infants reported that they were beginning to say words at home before they said words in the playroom, on average, 2 months earlier than the first month (FW - 1) in the FW window ( $M=10.3$ months; range $=8-15$ months). For four children, either the FW target and/or the observation before or after the FW target overlapped with the PreSp window. Therefore, developments in object play that might have been associated with the very earliest occurrence of words (as reported in the mothers' diaries) were identified in this study through the use of the 3-month PreSp baseline.

The occurrence of a Vocabulary Spurt (VS) was a measure of achievement in the transition to language within the single-word period. This was defined by a sharp increase in the number of different words used in the playroom from one month to the next and was obtained from developmental functions of vocabulary growth ${ }^{2}$ The identification of a VS was guided by the results of a pilot study of three of the children (Lifter, 1982). In the pilot study, a sharp increase in new words occurred in the observation in which at least 12 new words were learned since the previous observation, after at least 20 words had already appeared in each child's cumulative lexicon. The VS window consisted of the VS target observation and the observation immediately before the target (VS -1) and the month immediately after (VS +1). Again, the children differed widely in age at VS ( $M=19.4$ months; range $=13-25$ months). For one child, only one observation intervened between the FW and VS targets and was attributed to the VS window.

These two developments in language-beginning to say words and a sharp increase in the number and frequency of words-have long been considered evidence of major developments in early language that define the transition to language. A vocabulary spurt has been observed consistently in studies of individual children (e.g., Bloom, 1973; Corrigan, 1978; Dromi, 1982; Fein, 1979; Gopnik \& Meltzoff, 1987; Halliday, 1975; Lifter, 1982; McCarthy, 1954; McShane, 1980; Nelson, 1973a; Stern \& Stern, 1907) and is one of the discontinuities cited by Fischer, Pipp, and Bullock (1984) as evidence of qualitative developmental change.

\section{Reliability}

An analysis of reliability was performed by having two independent coders code two 15-min samples, from each of the three language periods, from six different children. Levels of agreement ranged from .80 to .93 for identification of object displacements, and from .92 to 1.00 for each of the subcategories of constructions. The children's speech and nonspeech vocalizations were transcribed initially by hand, by one observer. This paperand-pencil transcription was then verified in a second pass by another observer who entered all nonword vocalizations (in phonetic transcription) and word vocalizations (in traditional orthography) into the computer. Disagreements between the two transcriptions were resolved by both observers reviewing the video recording together. Disagreements were most often errors of omission, and where agreement could not be reached, the vocalization was not included in the analyses. Coding object play and transcribing speech were performed independently, by different persons.

\footnotetext{
${ }^{2}$ To identify a vocabulary spurt, cumulative lexicons were constructed and plotted in graph form for each of the children based on the number of new word types that were used at each playroom observation. The child's age at each observation was plotted on the abscissa, and the number of new words observed at that time was added cumulatively to the total number of new words from the preceding samples and then plotted on the ordinate, generating developmental functions of vocabulary growth. Slopes were calculated for each interval between successive observations in order to establish the rate of word increase for the interval as follows: The number of different word types used at one observation was subtracted from the number of different word types used in the immediately subsequent sample, and then that number was divided by the number of weeks between the two successive observations. Thus, the first appearance of a minimum slope of 3.0, that is, three new words learned per week which is the same as 12 new words learned between monthly observations, given a minimum of 20 words in the lexicon, was the operationalization of a sharp increase in word use. The criterion of a minimum of 20 words was set in order to establish confidence that the vocabulary spurt emerged as a substantive change in the children's language development. In fact, none of the infants presented a slope $>3.0$ in their cumulative lexicons prior to achieving a minimum vocabulary of 20 words (see Lifter, 1982, for graphs of three cumulative lexicons). Given these criteria, all the children presented a VS.
} 


\section{RESULTS}

Frequency of Displacements

To determine whether object displacements were characteristic of the children's actions with objects, we counted the frequency of displacements at each observation in the PreSp, FW, and VS windows. The frequency of displacements increased from $M=59$ at 9 months to $M=184$ at VS +1: PreSp, $M=83$, range = 59-108; FW, $M=$ 131 , range $=129-133$; VS, $M=179$, range $=170-184$. Thus, given the frequency with which the children moved objects in relation to one another (once every $27 \mathrm{sec}$, on average), we could assume that these actions were representative of what the infants did in their everyday activities and were, therefore, useful for examination of developments in object knowledge.

The first analysis of object displacements was an examination of the direction of movement in the children's object displacements, based on change in the relative frequencies of separations and constructions. Most of the children's early displacements were Separations in which they moved objects apart from one another. For example, $80 \%$ of the displacements at 9 months were Separations, as can be seen in the representation of the relative frequency of Constructions in Figure 2a. Constructions increased in relative frequency until they represented about half the children's displacements. The mean frequency of constructions for the observations in each period were: PreSp, $M=22.9$; FW, $M=60.4$; VS, $M=99.9$. Thus, the children progressed from moving objects apart to eventually moving objects together as often as they moved objects apart.

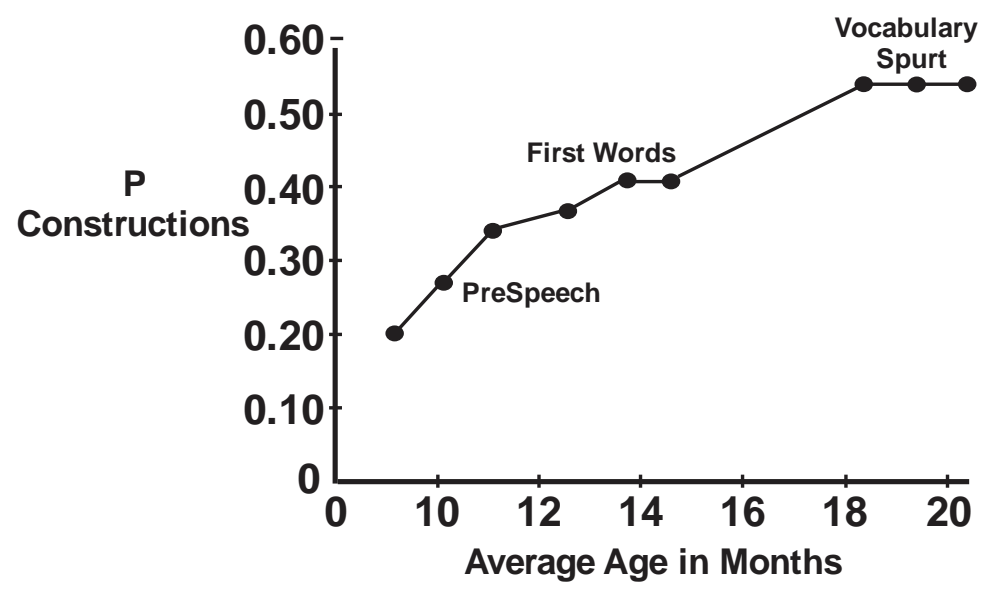

Figure 2a. Increase in Constructions according to age.

To determine whether this first development and subsequent developments in object knowledge over time were simply a function of increasing age, a grouping factor based on age of language achievement was included in the analyses. (See Emde and Harmon, 1984, and McCall, 1986, for discussion of the advantages of subgrouping on longitudinal research.) Because the infants differed widely in their ages at the time of developments in language, two subgroups of earlier and later language learners could be identified and compared. If the frequency of constructions increased, for example, from PreSp to VS, but the children who were older at VS produced more constructions than children who were younger, then the increase in constructions could be attributed to increase in chronological age rather than language achievement. On the other hand, if the frequency of constructions increased but the older and younger children did not differ in frequency of constructions, then we could infer that this particular development in object knowledge was associated with developments in language rather than chronological age.

The two subgroups were obtained by dividing the 14 infants according to whether age at FW was above or below the mean age of FW for the group as a whole $(M=13.8$ months, $S D=2.2)$. Seven infants, the earlier word learners (EWL), were below the group mean ( $M=12.1$ months, $S D=1.3$ ). Seven infants, the later word learners (LWL), were above the group mean $(M=15.5$ months, $S D=1.5)$. The two subgroups were significantly different in age of FW, $t(12)=-4.84, p<.001$, and in age of VS, $t(12)=-2.59, p=.024$. 
The relative frequency of Constructions (compared with Separations) by the subgroups of earlier and later language learners, in the three developmental periods, is presented in Figure 2b. In order to examine whether the increase in relative proportion of Constructions over time was significant, and if this trend was simply a function of increasing age, the proportion of Constructions for each infant in each period was subjected to an arcsine transformation, and transformed scores were used for a 3 (Periods: PreSp/FW/VS) x 2 (Groups: EWL/LWL) analysis of variance. The overall increase in proportion of Constructions was statistically significant, $\mathrm{F}(2,24)=39.39, p<.001$, the difference between the groups was also statistically significant, $\mathrm{F}(1,12)=4.85, p=$ .048 , but the Group x Period interaction was not statistically significant, $p=.301$. This analysis confirmed the results presented in Figure 2b.

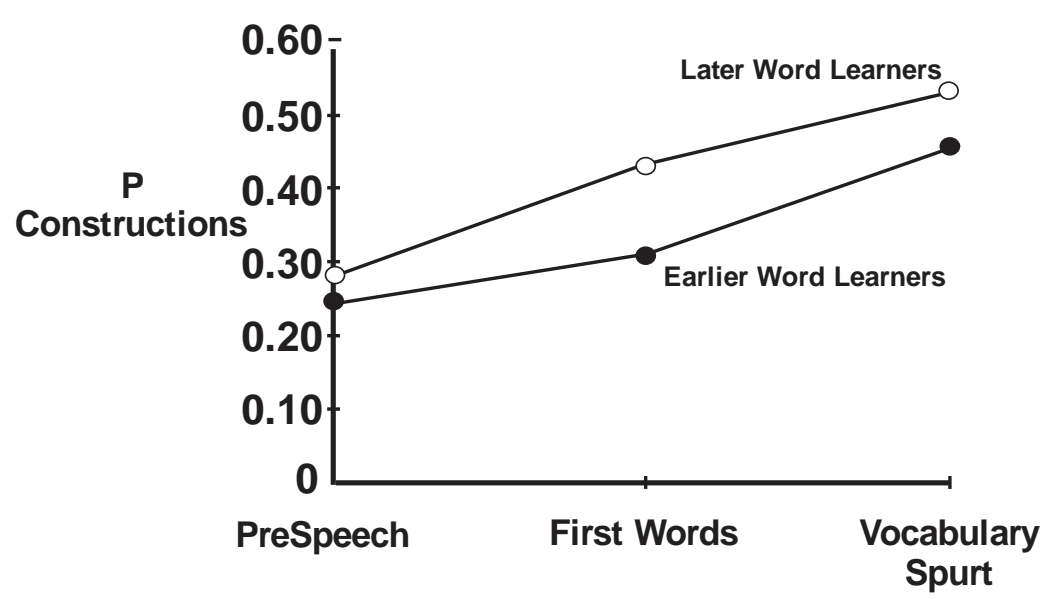

Figure 2b. Increase in Constructions by Earlier and Later Word Learners.

Constructions increased over time for both groups of infants. However, the infants who were older at the time of the developments in language produced more Constructions overall than the children who were younger at the time of developments in language. We conclude from this result that constructions increased in frequency and the increase was associated with chronological age.

The second analysis concerned developments in kinds of Constructions. The first distinction was between Given and Imposed constructions, and in all three periods about half the Constructions were Given and half were Imposed. However, changes occurred in the subcategories of Generic and Specific Imposed relations. The changes in Generic and Specific relations are presented in Figure 3a as proportions of Imposed constructions relative to Given constructions. While Given relations remained essentially the same, Imposed Generic constructions decreased as Specific constructions increased, as expected.

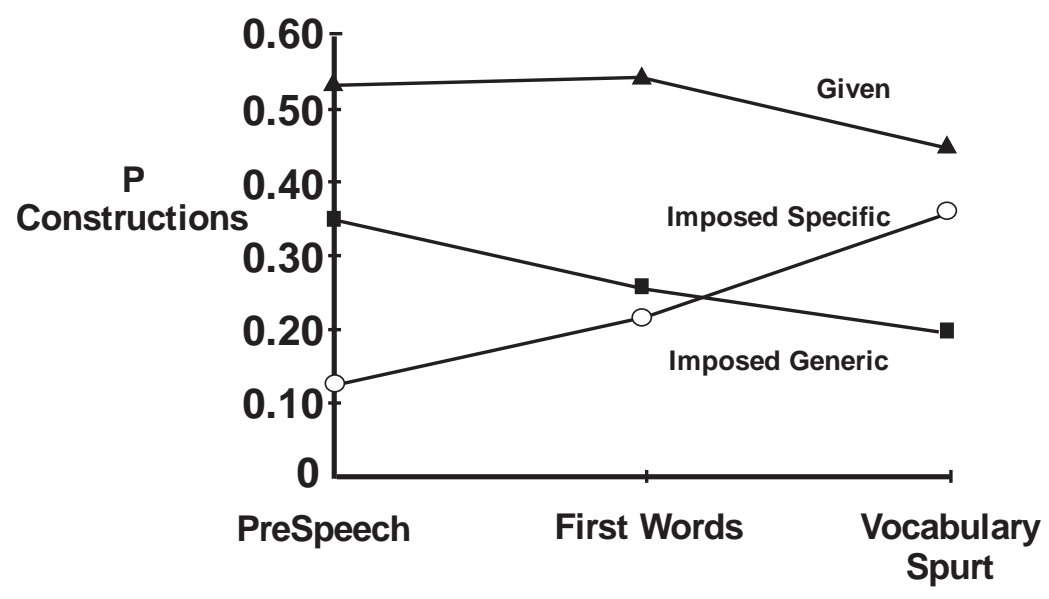

Figure 3a. Developments in subcategories of Constructions. 
To determine whether the increase in Specific constructions was simply a function of age, the proportion of Constructions that were Specific was compared for the three periods, with age of language development as a between-groups factor. The proportions are presented in Figure $3 \mathrm{~b}$ for the two subgroups in the three periods. The proportion for each infant in each period was subjected to an arcsine transformation, and transformed scores were used for a 3 (Periods: PreSp/FW/VS) x 2 (Groups: EWL/LWL) analysis of variance. The overall increase in the frequency of Specific relations was statistically significant, $\mathrm{F}(2,24)=24.49, p<.001$. The difference between the groups was not statistically significant $(p=.554)$ and the Group $\mathrm{x}$ Period interaction was not statistically significant $(p=.259)$. Both groups of infants increased in frequency of Specific relations. However, the infants who were older at the time of developments in language, and produced more Constructions overall, did not produce more Constructions that were Specific relations than the children who were younger at the time of developments in language. At no individual point (PreSp, FW, VS) was the difference between older and younger children significant; the apparent difference between the groups at FW was not significant, $p=.133$. We conclude from these results that although the children produced more Constructions overall as they grew older, the increase in relative proportion of Specific relations was associated with language achievement and not with chronological age. This result was subsequently confirmed by rank-order statistics, reported below.

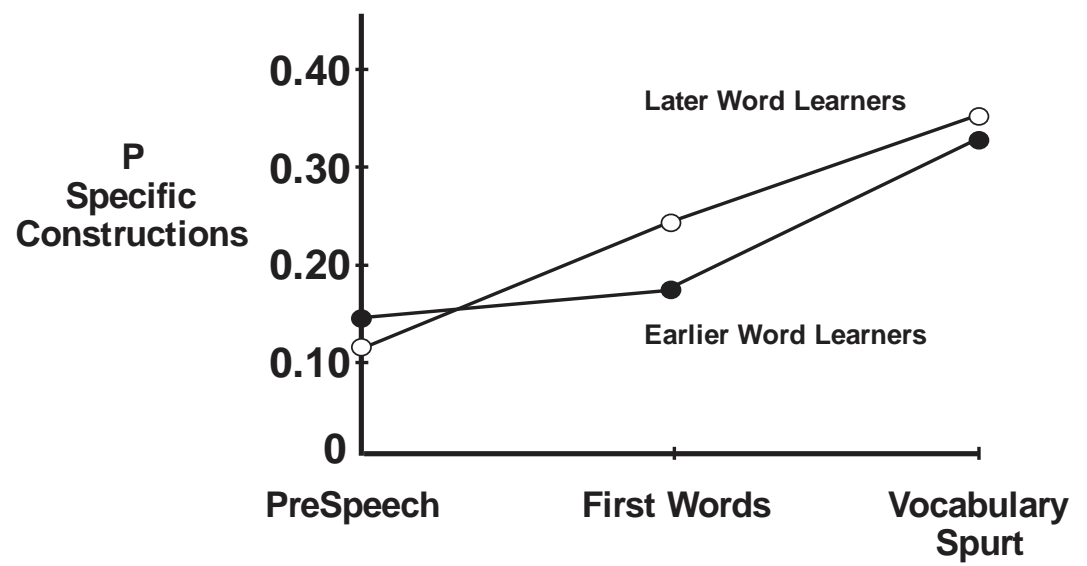

Figure 3b. Developments in Specific Constructions by later and earlier word learners.

\section{Sequence of Play Developments}

The sequence of development in the categories of displacements from PreSp to VS was determined for each child according to the criteria for emergence and achievement. Mean age at emergence and achievement of the major categories of Construct, Imposed, Specific, and Animate Surrogate constructions is presented in Figure 4. The sequence in the figure was the same for all the children. They all reached emergence (EMG) and achievement $(\mathrm{ACH})$ in Constructions and in Imposed and Specific relations in the same sequence, although at widely differing ages. The span in age range varied from 5 to 14 months for the different developments (e.g., the mean age for emergence of Constructions was 9.75 months; range 8- 13 months). Most of the children also reached emergence $(n=11)$ and achievement $(n=9)$ in Animate Surrogate relations.

The time interval between ages of emergence and achievement in the categories of Construct and Imposed was relatively small (2-3 months). This result means that when the children first began to construct relations between objects (emergence), little developmental change was required for reaching the level of competence specified by the achievement criteria in these activities. However, the difference in time between mean ages of emergence and achievement in the category of Specific relations was greater than 5 months, suggesting that the development of different capacities was required for achieving competence in constructing Specific relations between objects. The finding that achievement in Specific relations occurred within the VS window for 12 of the 14 children was significantly above chance, $p=.011$, two-tailed sign test. Of these 12 children, 2 reached achievement during the VS - 1 observation, 4 reached achievement during the VS observation, and 6 reached achievement during the VS +1 observation. These results support a model in which developments in language and play are related to each other by virtue of the relation of each to the same underlying developments in object knowledge. Thus, the 
different developments, VS and achievement in Specific relations, occurred within the 3-month window but were not serially ordered relative to one another within that window.

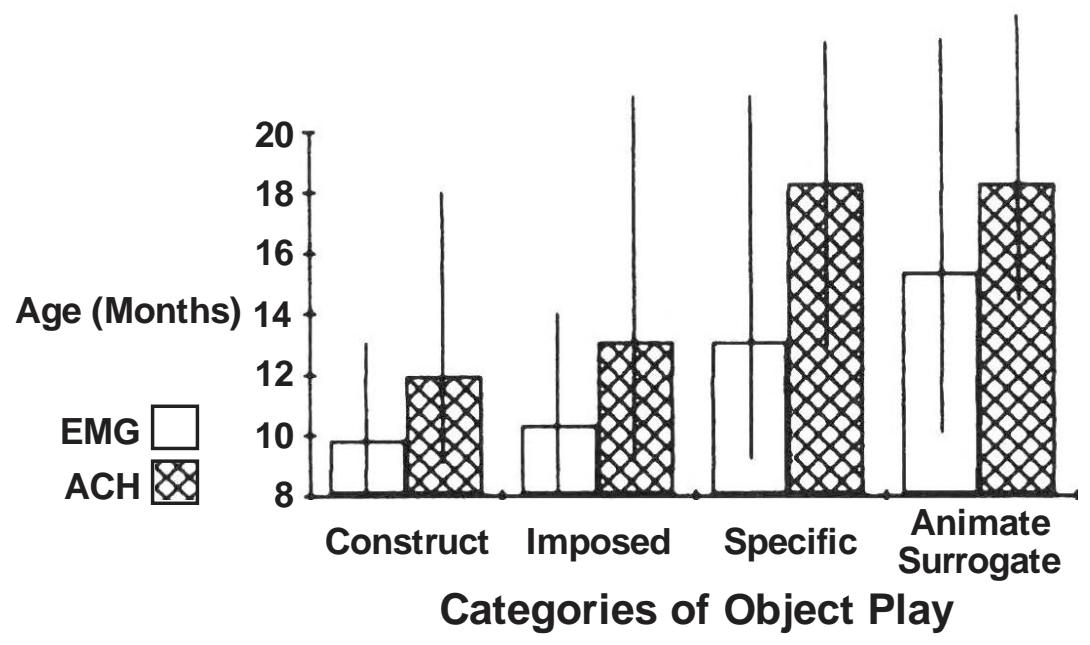

Figure 4. Mean ages of emergence (EMG) and achievement (ACH) in categories of object play

\section{Scale Performance}

Two attainments on the Scale of Object Permanence-Entry into Stage 6 and Representation-were inferred from Piaget's descriptions of the stages and attributions made by other researchers. The criterion used for entry into Stage 6(scale) was one invisible displacement with a single screen. The criterion for Representation(scale) was the reversed series of invisible displacements. All the children attained entry into Stage 6(scale) ( $M=12.09$ months, $S D=1.67$, range $=9-15$ months); 11 of the 14 children reached criterion for Representation(scale) $(M=19.36$ months, $S D=3.23$, range $=16-25$ months). (At least two successful performances were required for passing each task.)

The children were in Stage 6(scale) for most of the period under study, as was also found by Bates et al. (1979) and Corrigan (1978). Several children took as long as 10 months after passing the preceding task to reach criterion for Representation(scale) ( $M=4.00$ months, $S D=3.33)$, and three children did not reach Representation(scale) in task performance. These results may be due to differences in how the children approached the tasks and/or the requirements for administering the tasks. For example, administration of the criterion task requires that the child search directly under the final screen in the preceding serial displacement task so that the sequence of hiding could be reversed. However, some children tended to search persistently in order of hiding on the serial task, making it difficult to present the reversed series configuration.

\section{Comparisons of Object Play and Language with Scale Performance}

Correspondences between the developments in spontaneous play and performance on the object permanence scales are presented descriptively in Table 1. The earliest developments (Construct(EMG) and Imposed(EMG) $_{\left({ }_{(}\right)}$ occurred before Stage 6(scale) entry. The later developments in play (Specific(ACH) and Animate Surrogate(EMG, $\mathrm{ACH})$ were, with a single exception, developments after entry into Stage 6(scale) and before or during Representation(scale). All the other developments occurred before Representation(scale).

Scale performance was also compared with developments in language. All the children had entered Stage 6(scale) by the time they reached the FW transition. For the 11 children for whom representation(scale) could be identified, one achieved criterion by FW, 7 by VS, and 3 sometime after VS. At the time of the VS target, most of the children $(n=13)$ had passed scale Step 14 on the 15-point scale ( $M=14.50$ months, $S D=0.65)$. Therefore, the two language transitions we identified, FW and VS, bracketed the beginning and end of Stage 6 performance with the sensorimotor scales, as was expected. 
Table 1. Numbers of Children Reaching Criterion for Developments in Play: Before, During, and After Two Achievements on Object Permanence Scale

\begin{tabular}{|c|c|c|c|c|c|c|}
\hline \multirow{2}{*}{ Play Criterion } & \multicolumn{3}{|c|}{ Stage 6 Entry } & \multicolumn{3}{|c|}{ Representation } \\
\hline & Before & Duringa & After & Before & Duringa & After \\
\hline Construct $_{(\mathrm{EMG})}$ & (14) & & & (11) & & \\
\hline Construct $_{(\mathrm{ACH})}$ & 5 & 6 & 3 & 11 & & \\
\hline $\operatorname{Imposed}_{(\mathrm{EMG})}$ & (12) & (1) & (1) & (11) & & \\
\hline Imposed $_{(\mathrm{ACH})}$ & 5 & 3 & 6 & 11 & & \\
\hline Specific (EMG) $_{(\mathrm{B}}$ & (2) & (4) & (8) & (11) & & \\
\hline Specific $_{(\mathrm{ACH})}$ & & & 14 & 4 & 5 & 2 \\
\hline $\begin{array}{l}\text { Animate } \\
\text { Surrogate }_{(\mathrm{EMG})}\end{array}$ & (1) & & (10) & (7) & (1) & (1) \\
\hline $\begin{array}{l}\text { Animate } \\
\text { Surrogate }_{(\mathrm{ACH})}\end{array}$ & & & 9 & 2 & 2 & 3 \\
\hline
\end{tabular}

Note. The numbers for emergences (EMG) are noted in parentheses to distinguish them from numbers for achievements (ACH).

a"During" means that the criteria for play and scale performance were reached during the same monthly observation.

\section{Comparisons of Developments in Object Play and Language}

The intersection of developments in play and periods of language transition was examined in two separate procedures: scale analyses and the Friedman test. In the scale analyses, the developments in the four categories of play (Construct, Imposed, Specific, and Animate Surrogate) were examined in the three language periods (PreSpeech, First Words, and Vocabulary Spurt) to determine if their intersection formed an additive scale. This was done separately for emergences and achievements in play. The presence or absence of the criterion levels in the four categories of play development was dichotomized as 1 or 0 , respectively, for the 14 children in each language-related time period. The resulting matrix of 4 (Categories of Play) x 3 (Language Periods) x 14 children was tested using the SPSS-X RELIABILITY procedure. The result was an additive scale, confirmed by high multiple correlations among the items in the scale using the Guttman model $(\lambda 6$ (.8449) $>\lambda 2(.7953)$ (Guttman, 1945). This result is summarized in Table 2, which shows a pattern of achievements beginning with all zeros at PreSp and ending with all ones at VS. Achievements in Constructions and Imposed relations were associated with PreSp and FW, and achievements in Specific and Animate Surrogate relations were associated with VS.

In contrast to the scale formed from the intersection of play achievements with language period (Table 2), an additive scale was not formed when achievements in the play categories were organized according to the rank order of the ages of the individual children. This result is presented in Table 3 which illustrates the considerable variability in the children's ages when they reached criteria for the language targets (FW range $=10-17.3$ months of age; VS range $=25$ months of age). When subjected to a scale analysis, the results presented in Table 3 for FW and VS separately did not form scales due to zero variance among the items. Taken together, the results in Tables 2 and 3 support the conclusion that the intersections between achievements in categories of play and language period were independent of age. 
Table 2. Summary Scale of Achievements in the Categories of Play for all the Children Within the Three Language Windows

\begin{tabular}{lccccc}
\hline & \multicolumn{5}{c}{ Play Categories } \\
\cline { 2 - 6 } Period & Construct & Imposed & Specific & Animate Surrogate & $n$ \\
\hline PreSpeech & 0 & 0 & 0 & 0 & 6 \\
\hline First words & 1 & 0 & 0 & 0 & 0 \\
& 1 & 1 & 0 & 0 & 8 \\
\hline Vocabulary spurt & 0 & 0 & 0 & 0 & 1 \\
& 1 & 0 & 0 & 0 & 1 \\
& 1 & 1 & 0 & 0 & 10 \\
& 1 & 1 & 1 & 0 & 2 \\
\hline & 1 & 0 & 0 & 0 & 0 \\
& 1 & 0 & 0 & 0 & 0 \\
& 1 & 1 & 0 & 0 & 0 \\
& 1 & 1 & 1 & 0 & 5 \\
& 1 & & 1 & 1 & 9 \\
\hline
\end{tabular}

When the intersection of emergence levels for the play categories and language period was subjected to a Guttman scale analysis (42 entries from 14 children at each language-related time period), an additive scale was not formed. Nor were additive scales formed when emergences in the play categories were organized according to the rank order of the ages of the individual children at FW and at VS, a result similar to the presentation in Table 3 for achievement levels in play. Thus, in no instance was an additive scale formed when emergence levels of the play categories were examined in relation to language periods.

For half the children, the developments associated with FW (Construct ${ }_{(\mathrm{ACH})}, \operatorname{Imposed}_{(\mathrm{ACH})}$ ) did, in fact, occur just prior to FW (in PreSp). This was due, in part, to the closeness in time between the PreSp and FW language periods ( $M$ difference $=3.68$ months, $S D=2.20$ ) as compared with the greater time span between FW and VS ( $M$ difference $=5.55$ months, $S D=2.90$ ). In addition, the PreSp period in the playroom (9-11 months) coincided with the age ( $M=10.3$ months) of first words reported by the mothers of 10 of the children in their diaries. For the remaining children, the developments associated with the FW window occurred in either the FW -1, FW, or FW +1 observation. Thus, learning to construct relations between objects was closely associated with beginning to say words.

Table 3. Achievements at First Words and the Vocabulary Spurt According to Age

\begin{tabular}{llllll}
\hline & & \multicolumn{5}{c}{ Play Categories } \\
\cline { 3 - 6 } Child & $\begin{array}{l}\text { Age } \\
\text { (in Months) }\end{array}$ & Construct & Imposed & Specific & $\begin{array}{c}\text { Animate } \\
\text { Surrogate }\end{array}$ \\
\hline \multicolumn{2}{l}{ FIRST WORDS } & & & 0 & 0 \\
\hline Sh & 10 & 1 & 1 & 0 & 0 \\
Co & 11 & 1 & 1 & 0 & 0 \\
Da & 11,3 & 1 & 1 & 0 & 0 \\
Gr & 12 & 1 & 0 & 0 & 0 \\
Vi & 12 & 1 & 1 & 0 & 0 \\
Di & 13 & 1 & 1 & 0 & 0 \\
Ro & 13 & 1 & 1 & 0 & 0 \\
Al & 14 & 0 & 0 & 0 & 0 \\
Ha & 14 & 1 & 1 & 1 & 0 \\
Je & 14 & 1 & 1 & 0
\end{tabular}




\begin{tabular}{llllll}
$\mathrm{Cl}$ & 15 & 1 & 1 & 0 & 0 \\
$\mathrm{Re}$ & 16 & 1 & 1 & 0 & 0 \\
$\mathrm{Ch}$ & 17 & 1 & 1 & 1 & 0 \\
Le & 17,3 & 1 & 1 & 0 & 0 \\
VOCABULARY SPURT & & & & \\
$\mathrm{Sh}$ & 13 & 1 & 1 & 1 & 1 \\
$\mathrm{Da}$ & 16 & 1 & 1 & 1 & 1 \\
$\mathrm{Vi}$ & 16 & 1 & 1 & 1 & 0 \\
$\mathrm{Cl}$ & 17 & 1 & 1 & 1 & 1 \\
$\mathrm{Co}$ & 17 & 1 & 1 & 1 & 1 \\
$\mathrm{Di}$ & 18 & 1 & 1 & 1 & 1 \\
$\mathrm{Ha}$ & 19 & 1 & 1 & 1 & 0 \\
$\mathrm{Ro}$ & 19 & 1 & 1 & 1 & 1 \\
$\mathrm{Ch}$ & 20 & 1 & 1 & 1 & 1 \\
$\mathrm{Le}$ & 20,1 & 1 & 1 & 1 & 1 \\
$\mathrm{Gr}$ & 21 & 1 & 1 & 1 & 0 \\
$\mathrm{Al}$ & 23 & 1 & 1 & 1 & 0 \\
$\mathrm{Je}$ & 25 & 1 & 1 & 1 & 1 \\
$\mathrm{Re}$ & 25 & 1 & 1 & 1 & 0 \\
\hline
\end{tabular}

The intersection of developments in play and periods of language transition was further examined in a second set of analyses, using rank-order statistics to determine the stability among the children in the sequential developments within and between the domains of language and object knowledge. The occurrence of these developments was tested across the children using the Friedman test statistic (Hays, 1973; Siegel, 1956) for those developments that were observed for all the children (FW, VS, and emergences and achievements of Construct, Imposed, and Specific relations). Separate tests were performed for emergence and for achievement in play relative to FW and VS. These developments in play and language were ranked according to age at criterion for each of the individual children, with the assumption that $K$ individuals $(K=14)$ were observed under $J$ treatments $(J=5$; Hays, 1973). The resulting Friedman test statistics for emergence and achievement were 45.01 and 40.81, respectively, which, assuming chi-square distributions with 4 degrees of freedom, were significant at the .001 level. Thus, the rank order of developments within and between the domains of object knowledge and language developments was the same for this group of infants, despite the wide difference in their ages.

Table 4. Pairwise Comparisons of Developments in Play and Language

\begin{tabular}{|c|c|c|c|c|c|}
\hline EMERGENCE & Construct(EMG) $_{(\mathrm{s}}$ & $\operatorname{Imposed}_{(\mathrm{EMG})}$ & Specific $_{(\mathrm{EMG})}$ & FW & VS \\
\hline Construct (19.0) & & 0.57 & $1.86^{*}$ & $2.19^{* *}$ & $3.61^{* * *}$ \\
\hline Imposed (27.0) & & & 1.29 & 1.62 & $3.04^{* * *}$ \\
\hline Specific (45.0) & & & & 0.33 & 1.75 \\
\hline First words (49.5) & & & & & 1.42 \\
\hline
\end{tabular}

Vocabulary spurt

(69.5)

\begin{tabular}{llllll}
\hline ACHIEVEMENT & Construct $_{(\mathrm{ACH})}$ & $\operatorname{Imposed}_{(\mathrm{ACH})}$ & $\mathrm{FW}$ & Specific $_{(\mathrm{ACH})}$ & VS \\
\hline Construct (24.0) & & 0.39 & 0.54 & $2.75^{* * *}$ & $2.75^{* * *}$ \\
Imposed (29.5) & & 0.15 & $2.36^{* *}$ & $2.36^{* *}$ \\
First words (31.5) & & & $2.21^{* *}$ & $2.21^{* *}$ \\
Specific (62.5) & & & & 0.00 \\
Vocabulary spurt & & & &
\end{tabular}

(62.5)

${ }^{*} p<.05,{ }^{* *} p<.01,{ }^{* * *} p<.001$

Note. The developments listed across the top are abbreviations of these same developments listed along the left margin. In both cases, the order is from lowest to highest sums of ranks computed for each Friedman test. The actual sums of the ranks are listed in parentheses in the left margin. The comparisons are Scheffé contrasts-absolute differences between mean sums of ranks computed from the Friedman tests. 
Pairwise comparisons of these developments were tested statistically (Scheffé contrasts) to determine which developments were different from one another in accounting for the rank order of developments. The sums of the ranks of ages of emergence and achievement (from the Friedman test) were compared for every pair of developments to determine whether each differed significantly from the others.

The results for emergence are presented in the top half of Table 4. The emergence of Constructions (including any kind of Construction) occurred prior to FW, p<.050, whereas emergence of the subcategories of Imposed and Specific constructions were not different from FW. The emergence of Constructions and Imposed relations occurred prior to the VS, $\mathrm{p}<.001$, whereas the emergence of Specific relations was not different from the VS. Finally, the overall emergence of Constructions occurred prior to the emergence of the subcategory of Specific relations, $\mathrm{p}<.050$.

The results for achievement are presented in the bottom half of Table 4. Every development, except for achievement in Specific constructions, occurred prior to the VS, $p<.010$. Likewise, every development, except for the VS, occurred prior to achievement in Specific constructions, $p<.010$. Thus, two clusters of achievements in object knowledge and language were identified: The first was the association of FW with Construct(ACH), Imposed(ACH), Specific(EMG), and the second was the association of VS with Specific(ACH).

In sum, certain developments in object knowledge were more closely related to $\mathrm{FW}$, and other developments were more strongly related to VS. Furthermore, even though the developments in object knowledge and language occurred at widely different ages among the 14 children, the sequence of developments in the two domains and the associations between clusters of particular developments in the two domains were systematic for the group of children as a whole.

\section{DISCUSSION}

Because displacement activities occurred frequently in the infants' play activities, we can assume that developmental change in these displacements was evidence of developments in knowledge about objects. Object displacements changed in both form and content, in the same sequence and independently of age, for all the children during the period under study. Moreover, these developments were related to developments in language. The results of this study will be discussed in terms of the changes in the children's play activities that allowed us to infer developments in object knowledge during the period. Evidence from the two constellations of changes in language and object displacements will be discussed in terms of the support they provide for a relationship between developments in object knowledge and developments in language based on the similar developments in cognition that each require.

\section{Developments in Object Knowledge}

At the start of the study, before the emergence of words, the infants' displacements were predominantly, if not exclusively, separating activities. In order to separate two objects in a configuration, all the infant need do was take hold of one object and pull at it for the configuration to come apart. Once the objects were separated by the child (or the mother), they were available for Constructions. However, early in the period the infants did not, in general, construct relations between objects. In fact, most often, their mothers proceeded to reconstruct the configurations so that the infants could separate the objects again. The earliest displacements, then, were essentially unidirectional action patterns. These actions did not necessarily require an understanding of the relationship between the objects, nor even an understanding that the objects in the original configuration were indeed separate objects.

Separating displacements have not been described in the literature but appear to be related to the notion of "transitional search" (Piaget, 1954), in which infants remove a cover without awareness of the hidden object (i.e., without awareness of the relationship between the cover and the object). Transitional search was verified experimentally by Willats (1984), who reported its persistence for several months in the second half of the first

year. We suggest that transitional search is an epiphenomenon of separating as a basic sensorimotor schema through which infants begin to learn about objects as separate entities that can be related to one another. Learning how to construct a relation begins with learning how to take it apart. 
The first major change in displacements was the shift from separating activities (i.e., unidirectional action patterns) to the emergence and achievement of constructing activities (i.e., reversible action patterns). With Constructions, the children now moved objects together to create a configuration. This difference in the direction of movement and creation of a configuration entailed a reversal of action schemes that represents a reorganization of schemes with respect to objects in the Piagetian sense (e.g., Piaget, 1954). We suggest that the emergence of Constructions reflected the ability to think about objects in general, both as separate entities and in terms of reversible relations between them. This kind of general knowledge about objects is central to the development of object permanence as conceptualized by Piaget (1954) and, indeed, occurred at the time the children began to solve the tasks considered to mark the beginning of Stage 6 on the sensorimotor scale.

Other developments have been reported in the literature as evidence of major cognitive change in this same period from the end of the first to the beginning of the second year. Examples include the ability to group similar objects in space in spontaneous classifications (Langer, 1980; Nelson, 1973b; Ricciuti, 1965; Starkey, 1981) by looking for or manipulating objects from one category at a time (Sugarman, 1981, 1982); the dissociation of means from ends (McCall, Eichorn, \& Hogarty, 1977); and the ability to generate ideas about objects (Kagan, 1984; Zelazo \& Kearsley, 1980; Zelazo \& Leonard, 1983). We suggest that these developments and the developments observed in the present study reflect underlying changes in general object knowledge.

The emergence of the ability to think about objects as separate entities in order to bring two objects together into a reversible configuration provided the infant with the means to learn more and different relations between objects and to increasingly discriminate among the objects available for actions. To construct a relation between objects, the child had to either recall the configuration from memory or create a new configuration with one or both objects serving as the perceptual cue. These infants first learned the relations afforded by the objects when they (a) took apart and then reconstructed the configurations in which the objects had been originally presented to them (i.e., Given relations), or (b) constructed General relations of containment and support (i.e., Generic relations). In these cases, the recall of the configuration or the creation of a new but Generic configuration was closely tied to the data of perception. (See Bloom, Lifter, \& Broughton, 1985 and Lifter, 1982, for a report of finding activities in everyday play and for discussion of further developments in general object knowledge, i.e., changes in the children's procedures for finding objects for their constructing activities.)

Relational activities such as the Given and Generic constructions we observed have been discussed in studies of children's play (e.g., Belsky \& Most, 1981; Fenson, Kagan, Kearsley, \& Zelazo, 1976) as 'transitional' to the subsequent development of pretend play (which would include Animate Surrogate relations in the present study). However, we would make a stronger claim for the importance of early constructing activities. Constructing reflects a fundamental development in knowledge of objects in general that is prerequisite to acquiring knowledge about more particular characteristics of objects and the relations between them for the development of object concepts. Both developments, knowledge of objects in general and in particular, have been assumed to contribute to learning words (Bloom, 1973; Sinclair, 1970).

The second major change in displacements was in the kinds of relations the children constructed, and the sequence of these developments reflected another sort of change in object knowledge. The development of Imposed, Specific relations was evidence of more particular knowledge of objects that could be attributed to the development of object concepts. This conclusion finds support in a study by Lucariello (1987) in which activities that were similar to the Specific relations we have described were used as a behavioral index of concept formation in the same age range. Other conceptual developments that have been reported in this same period include the ability to spontaneously form two groupings of objects (Gopnik \& Meltzoff, 1987; Sugarman, 1982), which would require comparing the specific properties that distinguish objects from one another. Inanimate Specific relations required knowledge of the characteristics inherent in the physical properties of objects (e.g., a string and a hole in the beads). Animate Surrogate relations required additional, conventional knowledge of objects not afforded by their physical characteristics (e.g., the spoon and the doll). In both cases, the child had to recall a particular relation from memory, one that was more discrepant from the data of perception than the earlier Given and Generic constructions. The developments that occurred in this period in our study culminated with the VS and the development from Generic to Specific object constructions at the time the children began to solve the final Stage 6 tasks on the scales. These later developments presumably depend upon the specific knowledge about 
objects that is central to the formation of object concepts and the ability to access and represent that knowledge for both play and language.

Thus, at least three aspects of cognitive development contributed to and allowed the observed changes in object displacements to occur. One was knowledge about objects, both general (i.e., object permanence) and in particular (i.e., object concepts). Second was developments in recall and particularly the ability to use increasingly specific cues for recalling knowledge of objects and the relations between them. And, third was development in the capacity for representing aspects of that knowledge recalled from memory in the states of awareness underlying actions with the objects.

\section{Scale Performance and Object Knowledge}

These developments in object-general and object-specific knowledge were bracketed by the beginning and end of Stage 6 task performance with the sensorimotor scales. The long period of sensorimotor development that is often characterized in global terms as Stage 6 emerged in this study as a period of developmental change in knowledge of objects and the ability to access that knowledge for the contents of the mental states that underlie actions and saying words. This period was not a developmental plateau as has been suggested (e.g., Bates et al., 1979; Nelson, 1979). The period of development characterized as Stage 6 in Piaget's theory is transitional between sensorimotor and preoperational thought and constitutes a period of important developmental change, reflected in the present study in both language and play.

The two measures of object knowledge, one from spontaneous play and the other from scale performance, allowed different inferences about developments in cognition for comparison with language. Scale behaviors were diagnostic for assessing the child's level of sensorimotor development; the children were in Stage 6 (scale) for most of the single-word period. The analysis of the children's spontaneous play with objects, in contrast, provided details of developments in cognition that occurred within this level, and in the transitions between levels. The analysis of play also provided details of what a diagnostic level of sensorimotor development means in terms of everyday activities with objects.

\section{Object Knowledge and Language}

The results of the present study suggest that developments in the domains of language and object knowledge occur together and are integrated. The emergence of language (FW and the mothers' diary reports of early words spoken at home) was closely associated with emergence of the general knowledge that objects are separate entities and relations between them are reversible. These developments occurred as or just after the children began to pass the first scale items for Stage 6 of object permanence. Similarly, achievement in both language (VS) and object displacements (Specific relations) were associated with one another and with passing the final scale items for Stage 6 of object permanence. Essentially the same results were found in a study widely cited as demonstrating a loose or no relationship between language and object permanence (Corrigan, 1978):

"There was a general correspondence between onset of search for an invisibly displaced object (... Stage 6) and the onset of single-word utterances ... also. ... a general correspondence between attainment of the final rank of the object permanence scale. . . and an increase in the child's total vocabulary" (pp. 186-187).

Moreover, in the present study, despite the wide variation in the infants' ages when developments in language and play were reached, the relations between achievements in the two domains were consistent among them. This was true despite the fact that the relative frequency of constructions overall tended to be greater for the children who were older at the time of developments in language. We conclude that developments in play and language were not simply a function of age and general maturation, but, rather, were related to one another through the relation of each to developments in cognition, as Piaget (1954) described. This conclusion finds support in studies of atypical populations which have also demonstrated relations between play and language independently of chronological age (Beeghly \& Cicchetti, 1987; Sigman \& Mundy, 1987; Ungerer \& Sigman, 1981).

The results of the present study suggest a reconsideration of just how mental representation is important for language and for play. Acquiring a knowledge base and the procedures for accessing and representing aspects of knowledge in relation to the data of perception are the critical cognitive developments in infancy (Mandler, 1984). The two constellations of changes in both play and language, identified for all the children, were diagnostic of these developments. In play, the first was the transition that came with the ability to construct relations between 
objects after first having learned to take them apart. Seeing one object served as a cue for recalling its relation to another object and holding that relation in mind in the effort of constructing. FW was the corresponding development in language. After having learned a word by hearing it in relation to an item of perception, seeing an object or performing an action schema served as a cue for recalling a word to say it. We suggest that beginning to say words and learning to construct relations between objects reflect the general object knowledge that figures in the development of object permanence: reversibility and the ability to consider objects as separate entities. Developments in general object knowledge would appear to be necessary for the children to acquire the more particular knowledge of objects that is necessary for object concepts.

The second major change in play that had its correspondence in language was achievement of Specific constructions. The strongest relation between play and language in this study was between achievement in Specific relations and VS. We suggest that similar developments in cognition were required for each. The conclusion that Specific relations and the sharp increase in new words reflected developments in object concepts is consistent with the evidence for developments in object concepts in the same period reported by Sinclair (1970) and by Lucariello (1987). These results, along with recent work by other investigators (e.g., Gopnik \& Meltzoff, 1987; Nelson \& Lucariello, 1985), confirm the speculation in the literature (Bloom, 1973; Corrigan, 1983; Fischer \& Corrigan, 1981; McCune-Nicolich, 1981) that a vocabulary spurt in language toward the end of the second year is associated with substantive changes in cognition.

The strongest relations between developments in play and language in this study were for achievement levels (as confirmed with scale analyses and the Friedman test). Fewer consistencies were found between emergences in play and language. Using the Friedman test, the emergence of Specific relations was not different from either FW or VS. Furthermore, when emergence levels were used, the relationships between developments in language and play did not form a scale in the scale analysis. Emergence in the present study was similar to identification of the "most advanced behavior," which has been used to assign developmental level in other studies (e.g., Bates et al., 1979; Belsky \& Most, 1981; Nicolich, 1977; Smolak \& Levine, 1984). Our results suggest that the scatter and inconsistencies revealed when emergence levels were used is similar to the inconsistencies observed in other studies regarding the nature and extent of a developmental relation between language and cognition. In the present study, for example, early developments in play overlapped with the PreSp and FW windows.

The emergence of new categories of behavior indicates periods of transition. Achievement, in contrast, suggests a shift to mastery and stabilization of the knowledge that the activities required. If only emergence criteria had been used, the strong relationships between the VS and achievements in Specific and Animate Surrogate constructions would have been missed. The relatively long period between emergence and achievement of Specific relations, and between FW and VS, suggested the underlying cognitive development needed to support mastery and stabilization of knowledge about objects and words. Both language and play develop together because of the relation of each to the same underlying developments in cognition (Bates et al., 1979; Bloom, Lifter, \& Broughton, 1985; Piaget, 1954; Sinclair, 1970).

In the present study, we cast a wider net than target observations alone for examining relations between language and play and their relation to developments in cognition. We analyzed behavioral change at three times of developmental transition and used a 3-month window to examine developments at each transition. These developmental periods, along with two sets of criteria, one for emergence and another for achievement revealed clusters of developments in language and play. The cluster of developments associated with the VS occurred in a narrower transition window than the cluster associated with FW, which contributed to the stronger relationships observed at VS. However, the developments within each of the clusters did not occur in a linear lock-step relation with one another as correlational analyses would predict for relations between domains that are either serial or parallel. These results support the assertion that correlational analyses underestimate the complexity of the relation between developmental domains and may not be definitive for determining whether one exists (Belsky \& Most, 1981; Bloom et al., 1985; Smolak \& Levine, 1984). These results also support the usefulness of examining developmental change within a reasonably wide transition window (Connell \& Furman, 1984; Emde \& Harmon, 1984). 
In sum, two sorts of relations between developments in cognition and developments in language were inferred and were orthogonal to one another. First, developments within the FW cluster and developments within the VS cluster were each dependent upon different underlying changes in cognition. Second, the sequence of development between these two clusters was an empirical one, and we suggest that the cognitive developments that underlie each are logically invariant as well as sequential. The long period of sensorimotor Stage 6 entails learning about objects. The specific knowledge of object concepts that develops in this period would appear to require at least the general knowledge about objects that is characteristic of the level of object permanence existing at the beginning of Stage 6. However, although these developments in object permanence and object concepts were necessary for the developments in language and object displacements in play, we presume that the developments in cognition, by themselves, did not provide sufficient cause for either of the developments we observed. 


\section{REFERENCES}

Bates, E. (1976). Language in context. New York: Academic.

Bates, E., Begnigni, L., Bretherton, I., Camaioni, L., \& Volterra, V. (1979). The emergence of symbols: Communication and cognition in infancy. New York: Academic.

Beeghly, M., \& Cicchetti, D. (1987). An organizational approach to symbolic development in children with Down syndrome. In D. Cicchetti \& M. Beeghly (Eds.), New directions for child development, No. 36: Symbolic development in atypical children. San Francisco: Jossey Bass.

Belsky, J., \& Most, R. (1981). From exploration to play: A cross-sectional study of infant free play behavior. Developmental Psychology, 17, 630-639.

Bloom, L. (1970). Language development: Form and function in emerging grammars. Cambridge, MA: The M.I.T. Press.

Bloom, L. (1973). One word at a time: The use of single-word utterances before syntax. The Hague: Mouton.

Bloom, L., Lifter, K., \& Broughton, J. (1985). The convergence of early cognition and language in the second year of life: Problems in conceptualization and measurement. In M. Barrett (Ed.), Children's single-word speech. London: Wiley.

Bowerman, M. (1973). Early syntactic development: A cross-linguistic study with special reference to Finnish. Cambridge, England: Cambridge University Press.

Brown, R. (1973). A first language: The early stages. Cambridge, MA: Harvard University Press.

Connell, J., \& Furman, W. (1984). The study of transitions: Conceptual and methodological issues. In R. Emde \& R. Harmon (Eds.), Continuities and discontinuities in development. New York: Plenum.

Corrigan, R. (1978). Language development as related to Stage 6 object permanence development. Journal of Child Language, 5, 173-189.

Corrigan, R. (1983). The development of representational skills. In K. Fischer (Ed.), New directions in child development, No. 21: Levels and transitions in children's development. San Francisco: Jossey-Bass.

Dromi, E. (1982). In pursuit of meaningful words: A case study analysis of early lexical development. Unpublished doctoral dissertation, University of Kansas, Lawrence, KS.

Edwards, D. (1973). Sensory-motor intelligence and semantic relations in early grammar. Cognition, 2, $395-434$.

Emde, R., \& Harmon, R. (1984). Entering a new era in the search for developmental continuities. In R. Emde \& R. Harmon (Eds.), Continuities and discontinuities in development. New York: Plenum.

Fein, G. (1979). Echoes from the nursery: Piaget, Vygotsky, and the relationship between language and play. In E. Winner \& H. Gardner (Eds.), New directions for child development, No. 6: Fact, fiction and fantasy in childhood. San Francisco: Jossey-Bass.

Fenson, L., Kagan, J., Kearsley, R., \& Zelazo, P. (1976). The developmental progression of manipulative play in the first two years. Child Development, 47, 232-236.

Fischer, K., \& Corrigan, R. (1981). A skill approach to language development. In R. Stark (Ed.), Language behavior in infancy and early childhood. New York: Elsevier-North Holland.

Fischer, K., Pipp, S., \& Bullock, D. (1984). Detecting discontinuities in development: Method and measurement. In R. Emde \& R. Harmon (Eds.), Continuities and discontinuities in development. New York: Plenum.

Gopnik, A. (1984). The acquisition of gone and the development of the object concept. Journal of Child Language, 11, 213-292.

Gopnik, A., \& Meltzoff, A. (1987). The development of categorization in the second year and its relation to other cognitive and linguistic developments. Child Development, 58, 1523-1531.

Gratch, G. (1975). Recent studies based on Piaget's view of object concept development. In L. Cohen \& P. Salapatek (Eds.), Infant perception: From sensation to cognition (Vol. 2). New York: Academic.

Guttman, L. (1945). A basis for analyzing test-retest reliability. Psychometrika, 10, 255-282.

Halliday, M. (1975). Learning how to mean: Explorations in the development of language. London: Edward Arnold.

Hays, W. (1973). Statistics for the social sciences. New York: Holt, Rinehart \& Winston.

Huttenlocher, J., \& Higgins, E. (1978). Issues in the study of symbolic development. In J. Collins (Ed.), Minnesota symposia on child psychology, (Vol. 10). Hillsdale, NJ: Erlbaum. 
Ingram, D. (1978). Sensorimotor intelligence and language development. In A. Lock (Ed.), Action, gesture and symbol: The emergence of language. New York: Academic.

Kagan, J. (1984). The nature of the child. New York: Basic Books.

Langer, J. (1980). The origins of logic: Six to twelve months. New York: Academic.

Lifter, K. (1982). Development of object related behaviors during the transition from prelinguistic to linguistic communication (University Microfilms No. 8222429). Ann Arbor, MI.

Lucariello, J. (1987). Concept formation and its relation to word learning and use in the second year. Journal of Child Language, 14, 309-332.

Macnamara, J. (1972). Cognitive bases for language learning in infants. Psychological Review, 79, 1-13.

Mandler, J. (1984). Representation and recall in infancy. In M. Moscovitch (Ed.), Infant memory: Its relation to normal and pathological memory in humans and other animals. New York: Plenum.

McCall, R. (1986). Issues of stability and continuity in temperament research. In R. Plomin \& J. Dunn (Eds.), The study of temperament: Changes, continuities, and challenges. Hillsdale, NJ: Erlbaum.

McCall, R., Eichorn, D., \& Hogarty, P. (1977). Transitions in mental development. Monographs of the Society for Research in Child Development, 42(3, Serial No. 171).

McCarthy, D. (1954). Language development in children. In P. Mussen (Ed.), Carmichael's manual of child psychology. New York: Wiley.

McCune-Nicolich, L. (1981). The cognitive bases of relational words in the single-word period. Journal of Child Language, 8, 15-34.

McShane, J. (1980). Learning to talk. Cambridge, England: Cambridge University Press.

Menn, L., \& Hazelkorn, S. (1977). Now you see it, now you don't: Tracing the development of communicative competence. In J. Kegl (Ed.), Proceedings of the Seventh Annual Meeting of the Linguistic Society.

Miller, J., Chapman, R., Branston, M., \& Reichle, J. (1980). Language comprehension in sensorimotor Stages V and VI. Journal of Speech and Hearing Research, 23, 284-311.

Nelson, K. (1973a). Structure and strategy in learning to talk. Monographs of the Society for Research in Child Development, 38(1-2, Serial No. 149).

Nelson, K. (1973b). Some evidence for the cognitive primacy of categorization and its functional basis. MerrillPalmer Quarterly, 19, 21-39.

Nelson, K. (1979). The role of language in infant development. In M. Bornstein \& W. Kessen (Eds.), Psychological development from infancy: Image to intention. Hillsdale, NJ: Erl- baum.

Nelson, K., \& Lucariello, J. (1985). The development of meaning in first words. In M. Barrett (Ed.), Children's single word speech. London: Wiley.

Nicolich, L. (1977). Beyond sensorimotor intelligence: Assessment of symbolic maturity and pretend play. Merrill-Palmer Quarterly, 23, 89-99.

Piaget, J. (1954). The construction of reality in the child. New York: Basic Books.

Piaget, J., \& Inhelder, B. (1969). The psychology of the child. New York: Basic Books.

Ricciuti, H. (1965). Object grouping and selective ordering behavior in infants 12 to 24 months. Merrill-Palmer Quarterly, II, 129-148.

Rocissano, L. (1982). The emergence of social conventional behavior: Evidence from early object play. Social Cognition, I, 50-69.

Rubin, K., Fein, G., \& Vandenburg, B. (1983). Play. In E.M. Hetherington (Ed.), Handbook of child psychology (Vol. 4): Socialization, personality, social development. New York: Wiley.

Schlesinger, I. (1971). Production of utterances and language acquisition. In D. Slobin (Ed.), The ontogenesis of grammar. New York: Academic.

Siegel, L. (1981). Infant tests as predictors of cognitive and language development at two years. Child Development, 52, 545-557.

Siegel, S. (1956). Nonparametric methods for the behavioral sciences. New York: McGraw-Hill.

Sigman, M., \& Mundy, P. (1987). Symbolic processes in young autistic children. In D. Cicchetti \& M. Beeghly (Eds.), New directions for child development, No. 36: Symbolic development in atypical children. San Francisco: Jossey Bass.

Sinclair, H. (1970). The transition from sensory motor behavior to symbolic activity. Interchange, 1, 119-129. 
Slobin, D. (1973). Cognitive prerequisites for the development of grammar. In C. Ferguson \& D. Slobin (Eds.), Studies of child language development. New York: Holt, Rinehart \& Winston.

Smolak, L. (1982). Cognitive precursors of receptive vs. expressive language. Journal of Child Language, 9, 1322.

Smolak, L., \& Levine, M. (1984). Assessment of cognitive-linguistic relationships. Child Development, 55, 973980.

Starkey, D. (1981). The origins of concept formation: Object sorting and object preference in early infancy. Child Development, 52, 489-497.

Stern, C., \& Stern, W. (1907). Die kindersprache. Leipzig, Germany: Barth.

Sugarman, S. (1981). The cognitive basis of classification in very young children: An analysis of object-ordering trends. Child Development, 52, 1172-1178.

Sugarman, S. (1982). Developmental change in early representational intelligence: Evidence from spatial classification strategies and related verbal expressions. Cognitive Psychology, 14, 410-449.

Tomasello, M., \& Farrar, M. (1984). Cognitive bases of lexical development: Object permanence and relational words. Journal of Child Language, II, 477-493.

Ungerer, J., \& Sigman, M. (1981). Symbolic play and language comprehension in autistic children. Journal of the American Academy of Child Psychiatry, 20, 318-337.

Uzgiris, I., \& Hunt, J. (1975). Assessment in infancy. Urbana, IL: University of Illinois Press.

Willats, P. (1984). Stages in the development of intentional search by young infants. Developmental Psychology, 20, 389-396.

Zachry, W. (1972). The relation of language development to sensorimotor level in second-year infants. Unpublished doctoral dissertation, Memphis State University, Memphis, TN.

Zachry, W. (1978). Ordinality and interdependence of representation and language development in infancy. Child Development, 49, 681-687.

Zelazo, P., \& Kearsley, R. (1980). The emergence of functional play in infants: Evidence for a major cognitive transition. Journal of Applied Developmental Psychology, 1, 95-117.

Zelazo, P., \& Leonard, E. (1983). The dawn of active thought. In K. Fischer (Ed.), New directions for child development, No. 21: Levels and transitions in children's development. San Francisco: Jossey-Bass. 


\section{APPENDIX}

\section{Schedule of Toy Presentation}

A group of toys (the CORE TOYS) was on the floor in front of the camera at the beginning of the session when the child and mother entered the playroom. The five groups of toys were brought into the playroom at 8min intervals thereafter, in the order 1 through 5.

CORE TOYS: Bendable family figures (Mommy, Daddy, Baby); wooden peg people placed in the holes in the seesaw; wooden nesting/stacking boxes (nested); plastic child-size slide; inclined wooden roadway/bridge (connected) with small truck beside it; two-part slide (base and ramp connected) with four discs beside it.

GROUP 1: Plastic dump truck; bendable farm animals (horse, cow, calf, pig); wooden beads and the string, separately, in a box.

GROUP 2: Toy silverware in a tray; wooden lockbox with four closed, empty compartments; soft stuffed lamb; baby doll (one black, one white, depending on the child's ethnicity).

(SNACK)

GROUP 3: Wooden hammer/ball/frame set (assembled); wooden train pieces (unconnected); plastic nesting cups with lids (nested); plastic nesting boxes (nested).

GROUP 4: Cardboard box with cover; pillowcase; bendable family figures (boy, girl); bendable farm animals (colt, sheep, bull); toy silverware pieces.

GROUP 5: Large plastic bowl; plastic chunky nuts and bolts (unassembled); wooden fruit puzzle (assembled). 